\title{
A GENERALIZED SURVEILLANCE MODEL WITH APPLICATIONS TO SYSTEMS SAFETY
}

\author{
Hoang Pham, Senior Member, IEEE, and Minge Xie \\ Rutgers University \\ Piscataway, New Jersey 08854
}

\begin{abstract}
This paper presents a generalized surveillance model for predicting the performance of complex systems consisting of many subsystems (units). These subsystems are frequently inspected to keep the entire system operating satisfactorily. Systems of this type are encountered in many areas, including nuclear power plant, national defense system, transportation stations, medical monitoring control rooms, etc. The particular application that motivated a development of this model is an FAA project, where we were asked to develop a surveillance model to better understand both the inspection process and the repair station itself and to provide information that can be used to assist inspectors in scheduling and prioritizing their visits to the stations.

A distinguishing feature of this surveillance model is that it combines two mutually dependent stochastic processes. One is a two-stage stochastic process for the occurrence of unfavorable condition in an individual subsystem and the other is a non-homogeneous Poisson process (NHPP) for the frequency of surveillance.
\end{abstract}

\section{INTRODUCTION}

With the development of modern technologies and the advancement of our industrial society, various engineering systems $[8,11]$ have been developed and are becoming more complex. Many such systems, including nuclear power plants, national defense system, transportation stations, medical monitoring control rooms, etc., require frequent surveillance by certified personal, who must identify potential problems and keep the systems performing satisfactorily. For example, the Federal Aviation Administration (FAA) [3] is the regulatory agency for aviation safety in the Unites States. Their aviation safety inspectors need to quickly identify areas of air operation that may warrant additional surveillance or corrective action, in order to minimize the risk of the flying aircraft. Often a system consists of many subsystems (units) and each of these subsystems is frequently inspected to keep them operating satisfactorily. It is clear that the performance of a 
system depends on the human inspections and, on the other hand, the frequency of inspection visits and tests of systems should also relate to the subsystem functions.

In order to promote a better understanding of the mutual dependence of system performance and human surveillance and to make the inspection procedure efficient, in this paper we develop a generalized model which consists of a dual stochastic process for surveillance systems. The model is used to describe the behavior of the FAA certified airplane repair stations as well as the inspectors' visiting pattern. It identifies significant covariate factors that contribute to an unfavorable rating and provides information to assist inspectors in scheduling and prioritizing their planned visits to airplane repair stations. In the analysis, a Poisson regression technique is adapted to study the covariate factors that are critical to the subsystem. Also, to simplify our discussion, we assume an inspection result of a subsystem is a binary type, i.e., either a satisfactory (favorable) result or an unsatisfactory (unfavorable) condition. The approach developed can be easily extended to multiple inspection results, other than the binary type.

In the development of complex systems, the first prototypes produced will invariably contain design, engineering and inspection deficiencies. To identify performance and reliability measurements so that corrective actions may be taken, many reliability, availability and maintainability (RAM) models [6,7,12-16] have been developed during the last two decades using various methodologies, i.e., the non-homogeneous Poisson process [2,6,15], neural networks [9], Bayesian approach [4,12], renewal process [5], quasi-renewal process [16] or Markov process [7]. Some of these papers have recognized the human influence to the system performance. They, however, only consider a single process of the system where the inspection patterns are not studied. This paper presents a generalized surveillance model for predicting the performance of complex systems consisting of many subsystems (units). A distinguishing feature of this research is that we develop a general surveillance model consisting of two mutually dependent stochastic processes that includes the frequency of surveillance. We illustrate our developed surveillance model by evaluating the performance of the repair stations based on the information collected in the National Program Tracking and Recording Subsystem (NPTRS) and Vital Information Subsystem (VIS) databases. The model's results can be used to (i) analyze the performance of the repair stations, (ii) identify significant covariate factors that contribute to the unfavorable rating, and (iii) obtain guidelines which can be used to prioritize inspection activities. 


\section{MODEL DEVELOPMENT}

Consider a model consisting of two mutually dependent stochastic processes. One is a two-stage stochastic process for the occurrence of unfavorable condition in an individual repair station; the other is a non-homogeneous Poisson process (NHPP) for the frequency of surveillance. To our knowledge, this is the first surveillance model that includes both the frequency of surveillance and the occurrence of station unfavorable rating.

\section{A. Model Formulation}

\section{Notations}

$i \quad$ subsystem index, $i=1,2, \ldots, n$

$\mathbf{X}_{i}: \quad(p \times 1$ vector $)$ covariate (characteristics) variables associated with the $i^{\text {th }}$ subsystem

$t_{k}^{(i)} \quad$ the time of the $k^{\text {th }}$ visit by inspectors to the $i^{\text {th }}$ subsystem

$y_{k}^{(i)}$ : binary outcome ( 0 or 1$)$ assigned to the $i^{\text {th }}$ subsystem at the $k^{\text {th }}$ visit (corresponding to time $\left.t_{k}^{(i)}\right)$, i.e., the indicator variable of the occurrence of unfavorable conditions $y_{k}^{(i)}=1 \quad$ corresponds to the unfavorable rating $y_{k}^{(i)}=0 \quad$ corresponds to the favorable rating

$\mathrm{Z}_{k}^{(i)} \quad$ (random variable) the period when the $i^{\text {th }}$ subsystem is under favorable condition (problem free state) after the $(k-1)^{\text {th }}$ problem is fixed and before the $k^{\text {th }}$ problem occurs. $\mathrm{Z}_{k}^{(i)}$ follows an exponential distribution with a parameter function $\lambda_{Z}{ }^{(i)}(t)$.

$\mathrm{W}_{k}^{(i)}$ (random variable) the period when the $i^{\text {th }}$ subsystem is under unfavorable condition after the $k^{\text {th }}$ problem occurs and before the problem is detected/corrected

$\lambda_{I}{ }^{(i)}(t)$ the intensity function of the NHPP used to model the inspection visits

$\lambda_{Z}(t)$ the intensity function to model the occurrence of unfavorable rating

$\gamma \quad$ unknown parameters vector in $\lambda_{I}{ }^{(i)}(t)$

$\alpha, \beta \quad$ unknown parameters in $\lambda_{Z}{ }^{(i)}(t)$

B $(p \times 1$ vector $)$ regression parameters associated with the covariate variables $\mathbf{X}_{i}$

$r_{i} \quad$ a given constant in $\lambda_{Z}^{(i)}(t)$.

\section{A.1 Model for the Frequency of Surveillance}

The development of the model for the surveillance visits consists of the following considerations. 
First, inspection records are collected during the inspectors' visits to a subsystem. Second, it is clear that the frequency of surveillance has an impact on the subsystem as the intent of an inspection is to identify problem areas to assure that any unfavorable condition will be corrected. Third, the frequency of surveillance conducted on a subsystem also depends on the performance of the subsystem, since inspectors are more likely to schedule trips to problem-prone subsystems.

For the subsystem $i$ th, we assume that the frequency of surveillance follows a non-homogeneous Poisson process (NHPP) with a time-dependent intensity function $\lambda_{I}(t)$. For any given time $t$ between the $(\mathrm{k}-1)^{\text {th }}$ and the $k^{\text {th }}$ surveillance visit, i.e. $t_{k-1}{ }^{(i)}<t<t_{k}{ }^{(i)}$, we assume that the intensity function $\lambda_{I}{ }^{(i)}(t)$ has the following form

$$
\lambda_{I}^{(i)}(t)=\lambda_{0} e^{\mathrm{G}_{\mathrm{K}}^{(\mathrm{i})}(\mathrm{t} ; \gamma)}
$$

where parameter $\lambda_{0}$ is the baseline unknown constant of the intensity function. The form of the function $\mathrm{G}_{\mathrm{k}}{ }^{(i)}(\mathrm{t} ; \gamma)$ is assumed to be known but with unknown parameter vector $\gamma$ and is used to model the factors that have influence on the inspection pattern.

In this paper, we define the function $\mathrm{G}_{\mathrm{k}}{ }^{(i)}(\mathrm{t} ; \gamma)$ to be in the form of $\left.\gamma_{1} w_{\mathrm{k}}{ }^{(i)}(t)+\gamma_{2} \mathrm{I}_{\left(t-t_{k-1}\right.}>\mathrm{T}_{2}\right)$ where $\mathrm{I}$ is the indicator function. The development of the function $w_{\mathrm{k}}^{(i)}(t)$ depends on the performance of the $i^{\text {th }}$ subsystem in a recent past. As an example, we may define $w_{\mathrm{k}}{ }^{(i)}(t)$ to be the number of times that the $i$ th station received unfavorable ratings in the past $\mathrm{T}_{1}$ units of time prior to time $t$. That is, $w_{\mathrm{k}}{ }^{(i)}(t)=\Sigma \mathrm{y}_{\mathrm{k}}$, where the $\mathrm{y}_{\mathrm{k}}$ 's are the inspection results of the $i^{\text {th }}$ station in a period of $\mathrm{T}_{1}$ units of time prior to $t$. Usually we have $\gamma_{1} \square 0$, then $\gamma_{1} w_{\mathrm{k}}{ }^{(i)}(t)$ can be viewed as representing the fact that inspectors are more likely to visit a station that has had many unfavorable ratings in recent visits. If $\gamma_{1}=0$, then it means a station past history of unfavorable inspection results does not change the frequency of surveillance. If $\gamma_{1}>0$, then it means the inspectors are more likely to visit stations with more recent problems detected as compared to those with fewer problems. The larger the $\gamma_{1}$ is, the bigger the impact of the station history is.

The second term $\left.\gamma_{2} \mathrm{I}_{\left(t-t_{k-1}\right.}>\mathrm{T}_{2}\right)$ for $\gamma_{2} \square 0$ in $\mathrm{G}_{\mathrm{k}}{ }^{(i)}(\mathrm{t} ; \gamma)$ is developed to model the requirement (enforcement) that each station should increase the chance of scheduling an inspection if it has not been inspected during the past $T_{2}$ period of time. If $\gamma_{2}=0$, then it means the enforcement is not effective. 


\section{A.2 Model for the Occurrence of Unfavorable Rating at an Individual Subsystem}

As mentioned previously, in order to simplify our analysis, we categorize the outcomes of an inspection to be either a favorable or an unfavorable rating. In this case, we can use a two-state process to model the subsystem performance. For some systems, the operators may be able to detect and correct some problems without the presence of an inspector. From the inspection point of view, such information is often not available. Hence, the problems that are considered in this paper will only be the problems that are discovered by the inspectors. Other types of problems can be included in our analysis if further information is available.

We assume that each subsystem starts in a favorable condition. After a waiting period, say $Z_{1}$, a problem occurs. During this time period, an inspector may or may not have paid a visit to the subsystem. After a problem occurs, if it is not detected and corrected by the subsystem itself, the subsystem will remain in an unfavorable condition until an inspector comes and detects the problem. Then the problem(s) is corrected and the station returns to a favorable state. Starting from that time, it will stay in the favorable state for time period $Z_{2}$, at which time until the same or a different problem occurs. The station is now in an unfavorable state again. If the station does not detect the problem, the problem will be with the station until the next inspection. After the problem is corrected, the station returns to the favorable condition. Such a process is repeated as time progresses. In the process, we ignore the time period required for fixing the detected problems, as in most situations the time to fix a problem is relatively short.

Figure 1 illustrates a possible realization of such a process for a subsystem. In Figure 1, the subsystem remains problem-free for a period of time $Z_{1}$. During this time, an inspector comes once at time $t_{1}$, and no problem is detected. At the end of a period of time $Z_{1}$, a problem occurs. The subsystem is in an unfavorable condition. The subsystem stays in that condition for $W_{1}$ period until at time $t_{2}\left(=Z_{1}+W_{1}\right)$, an inspector comes, and the problem is fixed. Starting from $t_{2}$, the subsystem stays problem-free for a period of time $Z_{2}$. During this time, inspectors conduct two inspections at times $t_{3}$ and $t_{4}$. Then no problem is found at either inspection. At time $t_{2}+Z_{2}$, a problem occurs. The subsystem stays in this state for a period of time $W_{2}$. At time $t_{5}\left(=t_{2}+Z_{2}\right.$ $\left.+W_{2}\right)$, an inspector comes. The problem is detected and fixed, and the subsystem returns to a favorable state. The subsystem will repeat such two-state process as time progresses. The waiting times for a problem to occur after fixing the previous problem are $Z_{1}, Z_{2}, \ldots, Z_{j}$. 


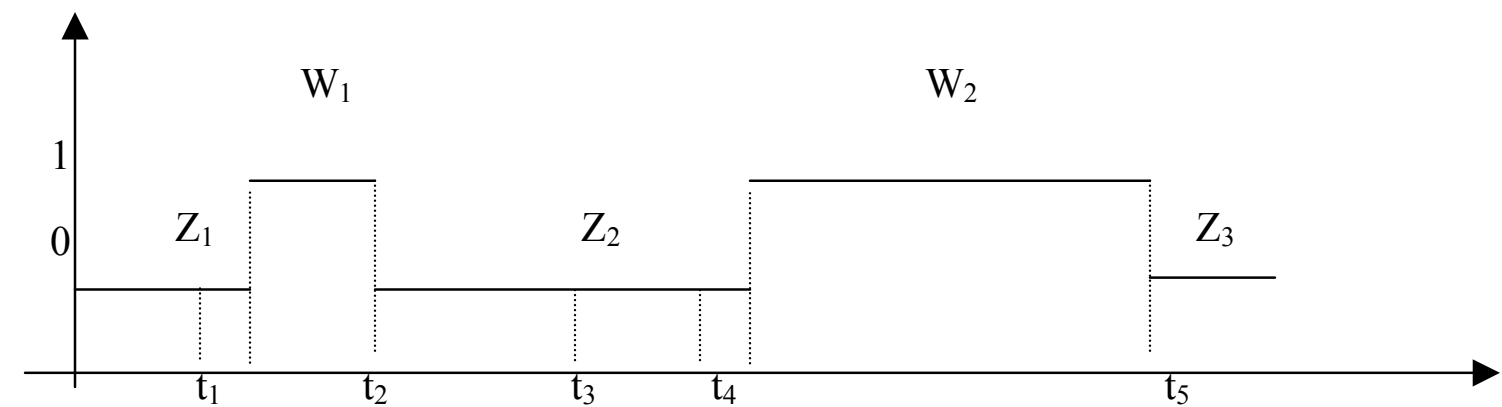

Figure 1: A Two-Stage Stochastic Process Scheme

In our analysis, the $Z_{\mathrm{i}}$ 's are modeled by an exponential distribution with a parameter $\lambda_{z}(t) . \lambda_{z}(t)$ is a function of time $t$. In order to identify significant covariate factors that contribute to the unfavorable rating, we assume that the intensity function of the $i^{\text {th }}$ station $\lambda_{Z}(t)$ has the following form

$$
\lambda_{Z}^{(i)}(t)=\alpha \beta r_{i}^{k-1} t^{\beta-1} e^{\mathbf{B X} i}, \quad \text { for } t_{k-1}<t<t_{k},
$$

where $r_{i}$ is a given constant and $\alpha, \beta$ and $\mathbf{B}$ are the unknown parameters. $\mathbf{B}^{T} \mathbf{X}_{i}$ is a linear regression term. The specification of such form is related to the Poisson log-linear model $[1,10]$ discussed in the statistical literature of generalized linear models. However, our specification is more general than that of the standard generalized linear models, as we allow $\lambda_{Z}(t)$ to be a function of $t$, in addition to a log-linear function of covariates of interest.

\section{B. Model Fitting}

We use the maximum likelihood method to estimate the unknown parameters of the proposed model above. The observations available to us are $\left\{\left(t_{k}^{(i)}, y_{k}^{(i)}\right)\right.$, for $k=1,2, \ldots, m_{i}$ and $i=1,2$, $\ldots, \mathrm{n}\}$. Denote $\theta$ as all the unknown parameters in the model. The joint density function for a given subsystem can be written as:

$\mathrm{x}$

Based on the model specification in Section 2 and from the standard computation, we obtain: 


$$
P_{\theta}\left(Y_{k}=y_{k} \mid y_{1}, \ldots, y_{k-1}, t_{1}, \ldots, t_{k}\right)=\left(e^{\int_{t_{k-1}}^{t_{k}} \lambda_{Z}(t) d t}-1\right)^{y_{k}}\left(e^{-\int_{t_{k-1}}^{t_{k}} \lambda_{Z}(t) d t}\right)
$$

and

$$
\mathrm{x}
$$

Therefore, the log-likelihood function for all observations will be

$$
\mathrm{x}
$$

From equations (2.1) and (2.2), we have:

$$
\mathrm{x}
$$

and

$$
\mathrm{x}
$$

When $\mathrm{G}_{\mathrm{k}}{ }^{(i)}(\mathrm{t} ; \gamma)$ takes the form of $\left.\gamma_{1} w_{\mathrm{k}}{ }^{(i)}(t)+\gamma_{2} \mathrm{I}_{(t-\mathrm{t}}{ }_{k-1}>\mathrm{T}_{2}\right)$, we have

$$
\mathrm{x}
$$

To estimate the unknown parameters $\theta$, we then maximize the log-likelihood function $l\left(\theta \mid\left\{\left(t_{k}{ }^{(i)}\right.\right.\right.$, $\left.y_{k}^{(i)}\right)$, for $k=1,2, \ldots, m_{i}$ and $\left.\left.i=1,2, \ldots, \mathrm{n}\right\}\right)$. Or equivalently, we can obtain $\square$ by solving the following system of equations

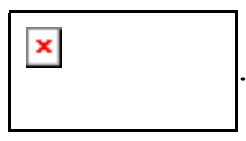

Based on the standard likelihood inference theory, it can be proved that such an estimator is asymptotically the most efficient. Since the information matrix is equal to 


$$
-\left.E\left[\frac{\partial^{2} l(\theta)}{\partial \theta^{2}}\right]\right|_{\theta=\hat{\theta}} \text { or }\left.E\left[\frac{\partial l(\theta)}{\partial \theta}\right]^{2}\right|_{\theta=\hat{\theta}}
$$

So the variance-covariance matrix of the estimator $\square$ can be estimated by

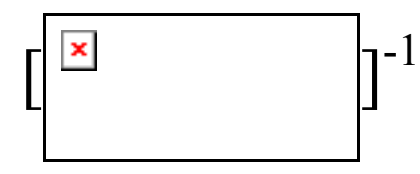

where $l_{i}(\theta)$ is the log-likelihood function for the $i^{\text {th }}$ subsystem.

\section{MODEL IMPLEMENTATION}

Safety assurance is an important aspect of a certificate holder's performance that is recognized by both the Federal Aviation Administration (FAA) and airlines. The FAA, as the regulatory agency responsible for aviation safety in the United States, has taken a proactive position to initiate research efforts in developing and validating safety performance measures (PMs) to benchmark air operators' safety performance. By analyzing the safety PMs, aviation safety inspectors are able to quickly identify areas of air operation that may warrant additional surveillance or corrective action, thereby safety risk of the public air transportation system is minimized.

To support an inspector's work in the areas of certification, surveillance, and investigation of repair stations, the FAA developed an information system, known as the Safety Performance Analysis System (SPAS) [3], in which PMs are being defined for implementation. These SPAS PMs can be used as a decision-support tool for inspectors since they integrate relevant information relating to the performance of an individual station. The information involved in these PMs may include the frequency of unfavorable ratings, personnel records, time interval between inspections, elapsed time from previous inspection, past data, and the average performance of similar stations.

In this section, we utilize the proposed surveillance model to carry out demonstrative analyses for domestic repair stations in the eastern region by: (1) evaluating the performance of an individual repair station, (2) identifying significant covariate factors (relevant characteristics) that contribute to unfavorable ratings, and (3) obtaining guidelines which can be used to prioritize inspection activities. 


\section{A. Data Collection and Description}

Data collected in these analyses are based on inspection results of the maintenance and avionics surveillance obtained from the Program Tracking and Reporting Subsystem (PTRS) and the Vital Information Subsystem (VIS) records [3]. Approximately, five years of past data from May 1994 to May 1999 was available. An inspection could result in one of the following:

. S (Satisfactory)

- I (Information)

. E (Enforcement)

. F (Follow up)

An $\mathrm{S}$ inspection result is considered as a favorable rating, while $\mathrm{E}$ or $\mathrm{F}$ is considered to be unfavorable. I (Information) is converted to either a favorable or an unfavorable rating according to inspector's opinion code. No missing data is included in this study.

In this paper, as a demonstration, we analyzed the following two data sets:

1. 'DC' data set: combined data set for the domestic repair stations inspected by either the maintenance or the avionics inspectors. The DC data set includes 477 repair stations.

2. 'D36' data set: a subset of DC, containing only the data of domestic stations inspected only by maintenance inspectors. This data set includes 421 repair stations.

The complete surveillance records of 3 repair stations in data set DC are shown in Table 1. The value 0 in the inspection result (column 2) represents a favorable rating while value 1 represents an unfavorable rating.

To improve the current capability of SPAS as a decision-support tool for inspectors, a number of relevant parameters (covariate factors) relating to the performance of an individual station are integrated into the calculation of the rate of unfavorable occurrences. The covariate factors taken into consideration include the followings:

$\mathrm{X}_{1}: \log 10$ (total employees)

$\mathrm{X}_{2}$ : the percentage of the certified mechanics among the total number of employees

$\mathrm{X}_{3}$ : the percentage of the repair men in total employees

$\mathrm{X}_{4}$ : the percentage of the non-certified mechanics in the total number of employees

$\mathrm{X}_{5}$ : the date that a repair station is certified. 
Table 1. Basic information of 3 repair stations in data set DC

\begin{tabular}{|c|c|c|c|c|c|c|c|}
\hline Station ID & $\begin{array}{c}\text { Inspection } \\
\text { Result }\end{array}$ & $\begin{array}{c}\text { Inspection } \\
\text { Completion } \\
\text { Date }\end{array}$ & $\begin{array}{c}\text { Total number } \\
\text { Of } \\
\text { Employees }\end{array}$ & $\begin{array}{c}\text { Number of } \\
\text { Certified } \\
\text { Mechanics }\end{array}$ & $\begin{array}{c}\text { Number of } \\
\text { Non-certified } \\
\text { Mechanics }\end{array}$ & $\begin{array}{c}\text { Number } \\
\text { Of Repair } \\
\text { Men }\end{array}$ & $\begin{array}{c}\text { Original } \\
\text { Establish } \\
\text { Date }\end{array}$ \\
\hline 1 & 0 & 8-Mar-96 & 6 & 0 & 2 & 4 & 27-Apr-70 \\
\hline 1 & 0 & 9-Feb-96 & 6 & 0 & 2 & 4 & 27-Apr-70 \\
\hline 1 & 0 & 12-Apr-96 & 6 & 0 & 2 & 4 & 27-Apr-70 \\
\hline 1 & 0 & 12-Feb-97 & 6 & 0 & 2 & 4 & 27-Apr-70 \\
\hline 1 & 1 & $24-F e b-98$ & 6 & 0 & 2 & 4 & 27-Apr-70 \\
\hline 1 & 0 & 29-Маy-98 & 6 & 0 & 2 & 4 & 27-Apr-70 \\
\hline 2 & 0 & 1-Aug-97 & 5 & 0 & 2 & 2 & 14-Feb-78 \\
\hline 2 & 0 & 5-Feb-97 & 5 & 0 & 2 & 2 & 14-Feb-78 \\
\hline 2 & 0 & 5-Sep-95 & 5 & 0 & 2 & 2 & $14-F e b-78$ \\
\hline 2 & 0 & 6-Jul-98 & 5 & 0 & 2 & 2 & 14-Feb-78 \\
\hline 2 & 0 & 7-Aug-97 & 5 & 0 & 2 & 2 & $14-F e b-78$ \\
\hline 2 & 0 & 12-Oct-95 & 5 & 0 & 2 & 2 & 14-Feb-78 \\
\hline 2 & 0 & 13-Nov-95 & 5 & 0 & 2 & 2 & 14-Feb-78 \\
\hline 2 & 1 & 15-Aug-96 & 5 & 0 & 2 & 2 & 14-Feb-78 \\
\hline 2 & 0 & 19-Jul-95 & 5 & 0 & 2 & 2 & 14-Feb-78 \\
\hline 2 & 0 & 20-Oct-98 & 5 & 0 & 2 & 2 & $14-F e b-78$ \\
\hline 2 & 1 & 23-Sep-96 & 5 & 0 & 2 & 2 & 14-Feb-78 \\
\hline 2 & 0 & 27-May-98 & 5 & 0 & 2 & 2 & $14-F e b-78$ \\
\hline 2 & 0 & 29-Nov-95 & 5 & 0 & 2 & 2 & 14-Feb-78 \\
\hline 2 & 0 & 31-Jul-97 & 5 & 0 & 2 & 2 & $14-F e b-78$ \\
\hline 3 & 0 & 5-Apr-99 & 4 & 3 & 1 & 0 & 26-Nov-79 \\
\hline 3 & 0 & 6-Nov-95 & 4 & 3 & 1 & 0 & 26-Nov-79 \\
\hline 3 & 0 & 11-Feb-97 & 4 & 3 & 1 & 0 & 26-Nov-79 \\
\hline 3 & 0 & 20-Feb-96 & 4 & 3 & 1 & 0 & 26-Nov-79 \\
\hline 3 & 0 & 25-Mar-98 & 4 & 3 & 1 & 0 & 26-Nov-79 \\
\hline 3 & 0 & 28-Oct-97 & 4 & 3 & 1 & 0 & 26-Nov-79 \\
\hline
\end{tabular}

Computations in this report are performed using the statistical software packages, SAS (Statistical Analysis Software package) and S-PLUS (a system for data analysis from MathSoft). A customized micro-program was written and incorporated into the statistical software tool SPLUS to help us quickly obtain the maximum likelihood estimates (MLE) and perform statistical inference for the proposed surveillance model. 


\section{B. Modeling Results for the Proposed NHPP Model}

For a given station, let $\mathrm{y}_{\mathrm{k}}$ be the inspection result (either value 0 or 1 , as in Table 1 ) at the time $\mathrm{t}_{\mathrm{k}}$, the completion time of the $k$ th inspection. As described earlier, we assume inspectors' visits follow a NHPP with intensity function $\lambda_{I}(\mathrm{t})$ while the occurrence of unfavorable rating in each repair station follows a two-state stochastic process with intensity rate $\lambda_{S}(t)$. The $T_{1}$ and $T_{2}$ in $\lambda_{I}(t)$ are both taken to be 12 months. The covariate factors considered include the five factors $\mathrm{X}_{1}, \mathrm{X}_{2}, \ldots, \mathrm{X}_{5}$ listed above.

For the data set DC, maximum likelihood estimates of all parameters and coefficients are listed in Table 2. It shows that the estimates of $\lambda_{0}$ and $\gamma_{1}$ are both positive and significant. This seems to confirm the fact that inspectors paid more visits to those repair stations that had more unfavorable ratings in the past 12 months as compared to others. The results in Table 2 also indicate that no single covariate factor seems significant. This may due to the vast diversity in the data set. However, the global affects of these factors are critical. For example, the larger the numerical value of linear combination of these factors, the shorter the waiting time for the unfavorable rating, indicating worsen future behavior of specific repair station.

Table 2. NHPP modeling results for data set DC

\begin{tabular}{|r|r|r|}
\hline Data DC & Value & Std.Error \\
\hline$\alpha$ & 0.0020415 & 0.0106298 \\
\hline$\beta$ & 1.4478712 & 1.1735413 \\
\hline$\lambda_{0}$ & 0.1986897 & 0.0284546 \\
\hline$\gamma_{1}$ & 0.1550324 & 0.0366495 \\
\hline$\gamma_{2}$ & 0.0000000 & 0.5098523 \\
\hline $\log 10\left(\right.$ TotEmply) $\left(\mathrm{x}_{1}\right)$ & 0.5900304 & 0.7429894 \\
\hline CertMech/TotEmply $\left(\mathrm{x}_{2}\right)$ & 0.8885833 & 1.5818333 \\
\hline RprMen/TotEmply $\left(\mathrm{x}_{3}\right)$ & 0.6759927 & 2.3244980 \\
\hline NonCertMech/TotEmply $\left(\mathrm{x}_{4}\right)$ & 0.4505002 & 1.5689656 \\
\hline NewIssueDate/12 $\left(\mathrm{x}_{5}\right)$ & 0.0117569 & 0.0360356 \\
\hline
\end{tabular}


From the results, we have $\lambda_{I}(\mathrm{t})$ and $\lambda_{S}(\mathrm{t})$ with the following forms,

$$
\begin{gathered}
\lambda_{I}(t)=(0.198690) e^{0.15503\left(\sum_{1 y r} y\right)} \\
\lambda_{s}(t)=(0.00204)(1.44787) t^{0.44787} e^{0.59003 x_{1}+0.88858 x_{2}+0.67599 x_{3}+0.45050 x_{4}+0.01176 x_{5}} .
\end{gathered}
$$

Table 3 lists all the MLE parameters and coefficients in our proposed model for data set D36. As we previously observed in preliminary data analysis, the data set D36 shares very similar properties with the data set DC. Since all the signs and levels of significance of the parameters are close in both cases, similar interpretation of the results then follows.

Table 3. NHPP modeling results for data set D36

\begin{tabular}{|r|r|r|}
\hline Data D36 & Value & Std. Error \\
\hline$\alpha$ & 0.0001649 & 0.0009530 \\
\hline$\beta$ & 1.8706570 & 1.2006743 \\
\hline$\lambda_{0}$ & 0.1318164 & 0.0202614 \\
\hline $\mathrm{r} 1$ & 0.1697728 & 0.0586521 \\
\hline $\mathrm{r} 2$ & 0.0000000 & 0.5833140 \\
\hline $\log 10$ (TotEmply) $\left(\mathrm{x}_{1}\right)$ & 0.6993509 & 1.1004831 \\
\hline CertMech/TotEmply $\left(\mathrm{x}_{2}\right)$ & 0.7218738 & 2.4592173 \\
\hline RprMen/TotEmply $\left(\mathrm{x}_{3}\right)$ & 0.5946047 & 3.2975450 \\
\hline NonCertMech/TotEmply $\left(\mathrm{x}_{4}\right)$ & 0.4546172 & 2.4960397 \\
\hline NewIssueDate/12 $\left(\mathrm{x}_{5}\right)$ & 0.0062341 & 0.0519131 \\
\hline
\end{tabular}

From the results, the corresponding NHPP intensity rates $\lambda_{I}(\mathrm{t})$ and $\lambda_{S}(\mathrm{t})$ for each individual station are:

$$
\begin{gathered}
\lambda_{I}(t)=(0.13182) e^{0.16977\left(\sum_{1 y r} y\right)} \\
\lambda_{S}(t)=(0.000165)(1.87066) t^{0.87066} e^{0.69935 x_{1}+0.72187 x_{2}+0.59460 x_{3}+0.45462 x_{4}+0.006234 x_{5}}
\end{gathered}
$$




\section{Prediction for Selected Repair Stations using NHPP Model}

We can also use the proposed model to predict the future performance of the repair stations. This information can help management to better understand the station performance and assist inspectors in scheduling and prioritizing his/her planned visits to repair station(s). We illustrate this by two examples with repair stations selected from the data sets DC and D36 respectively. The first example compares two stations with some similar features. One can compare the chances to see an unfavorable rating in a "future" visit to the stations and explore their differences. In the second example, we illustrate the results from an individual inspector's point of view. The chances to see an unfavorable rating in a "future" visit to the stations in charged by inspector BLC are listed. Such information can assist inspectors to prioritize his visits to stations.

\section{Example 1.}

We select two repair stations from the data set DC, say, Station A and Station B. Their information is summarized in Table 4. By investigating the personnel and past inspection information, we see that the ratios of all kinds of technical personnel (factors $\mathrm{X}_{2}, \mathrm{X}_{3}$, and $\mathrm{X}_{4}$ ) are almost same for these two stations, and they both have no unfavorable results in the year 1998. The differences between the twos are the amounts of time that elapsed from the last inspection, the total numbers of employees and the certified dates.

Table 4. Information of repair stations Station A and Station B

\begin{tabular}{|c|c|c|c|c|c|c|c|}
\hline Station ID & $\begin{array}{c}\text { Total } \\
\text { Number of } \\
\text { Employees }\end{array}$ & $\begin{array}{c}\text { No. of } \\
\text { Cert. } \\
\text { Mech. }\end{array}$ & $\begin{array}{c}\text { No. of } \\
\text { Non-Cert. } \\
\text { Mech. }\end{array}$ & $\begin{array}{c}\text { Number } \\
\text { of } \\
\text { Repairmen }\end{array}$ & $\begin{array}{c}\text { No. Unfav. } \\
\text { Vs. } \\
\text { No.Inspection }\end{array}$ & $\begin{array}{c}\text { Date of } \\
\text { Last } \\
\text { Inspection }\end{array}$ & $\begin{array}{c}\text { Original } \\
\text { Establish } \\
\text { Date }\end{array}$ \\
\hline A & 5 & 0 & 2 & 2 & $2 / 14$ & 20 -Oct-98 & 14-Feb-78 \\
\hline B & 20 & 0 & 9 & 8 & $1 / 11$ & 30 -Apr-99 & 04-Apr-88 \\
\hline
\end{tabular}

Assume "today" is August $2^{\text {nd }}, 1999$. Based on our model and the estimates of the model parameters (from fitting the data set DC), the probabilities of an unfavorable inspection result in a "future" visit are shown in Table 5. 
Table 5. Predicting the probability of unfavorable ratings

\begin{tabular}{|c|c|c|c|}
\hline Station ID & $\begin{array}{c}1 \text { month from } \\
\text { today }\end{array}$ & $\begin{array}{c}6 \text { months from } \\
\text { today }\end{array}$ & $\begin{array}{c}1 \text { year from } \\
\text { today }\end{array}$ \\
\hline A & 0.01204 & 0.02187 & 0.03072 \\
\hline B & 0.00610 & 0.01109 & 0.01519 \\
\hline
\end{tabular}

From Table 5, the chance for an inspector to detect an unfavorable condition during his/her "future" visit to Station A is almost double that to Station B, if the "future" is one month, six months or one year from "today". Station A is more likely to have problems in a near future.

\section{Example 2.}

Assume that the inspector BLC was responsible for six repair stations in eastern region during the last five years. The basic information of these six repair stations is shown in Table 6 .

Table 6. Available repair stations inspected by inspector BLC

\begin{tabular}{|c|c|c|c|c|c|c|c|}
\hline Station ID & $\begin{array}{c}\text { Total } \\
\text { No. of } \\
\text { Employees }\end{array}$ & $\begin{array}{c}\text { No. of } \\
\text { Cert. } \\
\text { Mech. }\end{array}$ & $\begin{array}{c}\text { No. of } \\
\text { Non-Cert. } \\
\text { Mech. }\end{array}$ & $\begin{array}{c}\text { Number } \\
\text { Of } \\
\text { Repairmen }\end{array}$ & $\begin{array}{c}\text { No. Unfav. } \\
\text { Vs. } \\
\text { No.Inspectn }\end{array}$ & $\begin{array}{c}\text { Date of } \\
\text { Last } \\
\text { Inspection }\end{array}$ & $\begin{array}{c}\text { Original } \\
\text { Establish } \\
\text { Date }\end{array}$ \\
\hline A & 14 & 3 & 11 & 0 & $0 / 11$ & 11-Jan-99 & 01-Aug-95 \\
\hline B & 3 & 3 & 0 & 0 & $0 / 5$ & 22-Jun-98 & 01-Jul-70 \\
\hline C & 18 & 12 & 3 & 3 & $4 / 17$ & 21-Jan-99 & 06-Jun-60 \\
\hline D & 28 & 21 & 3 & 4 & $2 / 9$ & 12-Jan-99 & 06-Jun-72 \\
\hline E & 5 & 1 & 3 & 1 & $1 / 12$ & 24-Jun-98 & 26-Oct-89 \\
\hline F & 8 & 4 & 4 & 0 & $5 / 16$ & 27-Aug-98 & 02-Apr-93 \\
\hline
\end{tabular}

Assume "today" is August $2^{\text {nd }}, 1999$. Based on NHPP model and maximum likelihood estimates of all parameters and coefficients for data set D36, the probability for inspector BLC to see an unfavorable condition in a "future" visit to an individual repair station is shown in Table 7. The values associated to Station E are the highest. Table 7 indicates that a "future" visit to Station E will be more likely to see an unfavorable inspection result compared to the other five stations. Repair stations Station B and Station F are the next two. What these three stations have in common is that the times of last inspection are all in middle 1998, much further back than the last inspections of the other three stations. Among the three stations last inspected in January 
1999, suppose the inspector decides to inspect one of them one month later, he is most likely to see an unfavorable inspection result in Station C, followed by Station D. Examine the past performances of these three stations (Table 6, column 6), we can see that STATION-C had the most problems, followed by Station D.

Table 7. Chance to see Unfav. In a "future" visit

\begin{tabular}{|c|c|c|c|}
\hline Station ID & $\begin{array}{c}1 \text { month from } \\
\text { today }\end{array}$ & $\begin{array}{c}6 \text { months from } \\
\text { today }\end{array}$ & $\begin{array}{c}1 \text { year from } \\
\text { today }\end{array}$ \\
\hline A & 0.01702 & 0.05482 & 0.09182 \\
\hline B & 0.08672 & 0.12740 & 0.16823 \\
\hline C & 0.01497 & 0.05565 & 0.09648 \\
\hline D & 0.00900 & 0.02728 & 0.04220 \\
\hline E & 0.08964 & 0.13379 & 0.17965 \\
\hline F & 0.06253 & 0.10266 & 0.14273 \\
\hline
\end{tabular}

\section{CONCLUSIONS}

The dual-processes model that we developed in Section 2 takes into account many factors and situations that may influence inspection result of FAA repair stations. It's flexible and comprehensive as involving in stochastic process, which usually can afford satisfactory simulations to realistic maintenance systems. In this study, the NHPP model not only identifies covariate factors that contribute to the unfavorable rating of repair stations but also provides guidelines that can be used to prioritize future inspection activities.

It is, however, worth to extend this study by incorporating the following issue. As we know, it often takes time for operators in the subsystems to correct problems. In practice, the period from the time the problem is detected to the time the problem is corrected is not zero. The actual time interval between the last inspection and an occurrence of a new problem (i.e., $Z_{i}$ 's) should include the period of fixing problems. So the $Z_{i}$ 's values should be greater than it is supposed to be if the problems can be fixed instantly. 


\section{ACKNOWLEDGMENT}

This research was supported in part by the FAA William J. Hughes Technical Center under Grant 98-G-006 and by the NSF DMS-9803273. We thank the Editor and the referees for their useful suggestions. We also want to thank Loan Pham, Xiaolin Teng and Xiaolan Song for their assistances in data management and computing.

\section{REFERENCES}

[1] A. Agresti, An Introduction to Categorical Data Analysis. Wiley \& Sons, Inc., New York, 1996

[2] H.E. Ascher andH. Feingold, Repairable Systems Reliability, In Lecture notes in Statistics, vol. 7, Marcel Dekker, New York, 1984

[3] "FAR Part 145 Repair Station PTRS Data: Analysis Report", FAA William J. Hughes Technical Center, Draft Report, October 1996

[4] J.R. Boston, "A Signal Detection System Based on Dempster-Shafer Theory and Comparison to Fuzzy Detection," IEEE Trans, On Systems, Man, and Cybernetics - Part C, vol. 30, no. 1,2000

[5] D.R. Cox and V. Isham, Point Processes, Chapman and Hall, London, 1980

[6] M.J. Crowder, A.C. Kimber, R.L. Smith, and T.J. Sweeting, Statistical Analysis of Reliability Data, Chapman and Hall, London, 1991

[7] B.V. Gnedenko and I.A. Ushakov, Probabilistic Reliability Engineering, Wiley \& Son, 1995

[8] M. T. Isaai and M. G. Singh, "On Object-Oriented, Constraint-Based Heuristic for a Class of Passenger-Train Scheduling Problems," IEEE Trans. On Systems, Man, and Cybernetics - Part C, vol. 30, no. 1, February 2000

[9] Y.H. Kim and F.L. Lewis, "Optimal Design of CMAC Neural Network Controller for Robot Manipulators," IEEE Trans. On Systems, Man, and Cybernetics - Part C, vol. 30, 
no. 1, February 2000

[10] P. McCullagh and J.A. Nelder, Generalized Linear Models, 2nd Edition, London: Chapman \& Hall, 1989

[11] E. R. Peterson and J. Taylor, "A Structured Model for Rail Line Simulation and Optimization, “ Transportation Science, vol. 16, no. 2, 1982

[12] L. Pham and H. Pham, "Software Reliability Models with Time-Dependent Hazard Function Based on Bayesian Approach," IEEE Trans. on Systems, Man, and Cybernetics, vol. 30 , no. 1,2000

[13] H. Pham and H. Wang, "Imperfect Maintenance," European Journal of Operational Research, vol. 94, 1996

[14] H. Pham and H. Wang, "Optimal Opportunistic Maintenance of a k-out-of-n System with Imperfect PM and Partial Failure,” Naval Research Logistics, vol. 47, 2000

[15] H. Pham, Software Reliability. Springer-Verlag, 2000

[16] H. Pham and H. Wang, "A Quasi-Renewal Process for Software Reliability and Testing Costs," IEEE Trans. on Systems, Man, and Cybernetics A, vol. 31, no. 6, 2001

\begin{abstract}
AUTHORS
Hoang Pham (S'89-M'89-SM'92) received the B.S. degree in mathematics, B.S. degree in computer science, both with high honors, from Northeastern Illinois University, Chicago, the M.S. degree in statistics from the University of Illinois, Urbana-Champaign, and the M.S. and Ph.D. degrees in industrial engineering from the State University of New York at Buffalo, in 1982, 1984, 1988, and 1989, respectively. He is an Associate Professor with the Department of Industrial Engineering at Rutgers University, Piscataway, NJ. Before joining Rutgers, he was a senior engineering specialist at the Boeing Company, Seattle, and the Idaho National Engineering Laboratory, Idaho Falls. His research interests include software reliability, faulttolerant computing, reliability modeling, maintenance, environmental risk assessment, and optimization.

He is the author of Software Reliability (Springer-Verlag, 2000) and the editor of ten volumes. He has published more than 70 journal articles and 15 book chapters. Among his edited books are Recent Advances in Reliability and Quality Engineering (World Scientific, 2001), Software Reliability and Testing (New York: IEEE Computer Society Press, 1995), and Fault-Tolerant
\end{abstract}


Software Systems: Techniques and Applications (New York: IEEE Computer Society Press, 1992). He is currently editing the Reliability Engineering Handbook (Springer-Verlag, Fall 2002).

He is editor-in-chief of the International Journal of Reliability, Quality and Safety Engineering and was Guest Editor of the IEEE Trans. on Reliability, Journal of Systems and Software, the International Journal of Modeling and Simulation, and IEEE Communications. He is an editorial board member of the International Journal of Systems Science, Journal of Computer and Software Engineering, IIE Trans. on Quality and Reliability, and the International Journal of Plant Engineering and Management. He has been conference chair and program chair of many international conferences and is currently the General Chair of the Eighth International Conference on Reliability and Quality in Design will be held in Anaheim, CA, August 2002. He is a senior member of the IEEE, IIE and is listed in Who's Who in the World, Who's Who in America, Who's Who in Science and Engineering.

Minge Xie is Assistant Professor with the Department of Statistics, Rutgers University. His main area of research is development of statistical theory and methodology with emphasis on statistical modeling and interdisciplinary research. He obtained his B.S. degree in Mathematics with high honor from the University of Science and Technology of China (USTC) and M.S. and $\mathrm{Ph} . \mathrm{D}$. degrees in Statistics from University of Illinois at Urbana-Champaign (UIUC). 
4/10/2002

c:Imsdocljournal\IEEE_SMC_Repair_FINAL_April2002 